10-1-2018

\title{
Complications Associated with Volar Locking Plate Fixation of Distal Radial Fractures.
}

Todd H. Alter

Thomas Jefferson University

Asif M. llyas

Thomas Jefferson University

Follow this and additional works at: https://jdc.jefferson.edu/rothman_institute

Part of the Orthopedics Commons

Let us know how access to this document benefits you

\section{Recommended Citation}

Alter, Todd H. and Ilyas, Asif M., "Complications Associated with Volar Locking Plate Fixation of Distal Radial Fractures." (2018). Rothman Institute Faculty Papers. Paper 109.

https://jdc.jefferson.edu/rothman_institute/109

This Article is brought to you for free and open access by the Jefferson Digital Commons. The Jefferson Digital Commons is a service of Thomas Jefferson University's Center for Teaching and Learning (CTL). The Commons is a showcase for Jefferson books and journals, peer-reviewed scholarly publications, unique historical collections from the University archives, and teaching tools. The Jefferson Digital Commons allows researchers and interested readers anywhere in the world to learn about and keep up to date with Jefferson scholarship. This article has been accepted for inclusion in Rothman Institute Faculty Papers by an authorized administrator of the Jefferson Digital Commons. For more information, please contact: JeffersonDigitalCommons@jefferson.edu. 
1 Complications Associated with Volar Locking Plate Fixation of Distal Radius Fractures 


\section{INTRODUCTION:}

Distal radius fractures are among the most common orthopaedic injuries. Of 590,193

fractures of the upper extremity documented in the United States in 2009, distal radius fractures were the most common.(1) Additionally, they comprise one-sixth of all fractures seen in the emergency room.(2) In recent years, incidence of this already common fracture has continued to increase in pediatric, adult, and elderly populations alike.(3)

However, despite the high incidence of distal radius fractures, consensus regarding optimal treatment strategy still does not exist. Current treatment options include closed reduction, closed reduction with percutaneous pinning, intramedullary fixation, external fixation, and various open reduction and internal fixation strategies. $(4,5)$ Of these, open reduction and internal fixation with plates has seen a steady increase in use over the past two decades due to purported faster functional recovery and better radiographic alignment,(6) although better radiographic outcome does not necessarily translate to better long-term functional outcome in all groups. $(7,8)$ During this time there has been a simultaneous decreased use of dorsal plating due to concerns for extensor tendon irritation,(9) and a concomitant increase in the use of volar locked plating of distal radius fractures, particularly among newer surgeons.(10)

Volar locked plating of distal radius fractures has grown in popularity for several reasons including a consistent and reproducible surgical approach, broad range of fractures patterns that a volar plate can treat, and a reasonable complication profile compared to other operative fixation methods with a reportedly lesser rate of tendon injury.(11) However, there remain fractures that should not be treated with volar plating, including highly comminuted fractures which may be better managed with wrist arthrodesis. $(12,13)$ Additionally, the exact incidence and pattern of complications from volar locking plates for distal radius fractures are not well understood. 
EVOLUTION OF VOLAR LOCKING PLATE TECHNOLOGY

Volar plating of distal radius fractures has been a surgical option since the introduction of

28 AO principles of fracture fixation. Initially, volar plates were primarily indicated for buttress reduction and fixation of volar shear fractures, aka volar Barton's fractures.(14, 15) (FIGURE 1) Later, the indication for volar plating increased with the introduction of non-locked but lower profile volar plates with increased screw fixation options and smaller subchondral screws, such as the volar T plate (FIGURE 2).(16) Although popular upon their introduction, these volar plates still required bicortical fixation of the distal subchondral screws resulting in prominent and sharper screws dorsally putting the dorsal extensor tendons at risk.(17-19) The original nonstyloid, targeting higher quality bone. It also facilitated avoidance of joint penetration.(26) 
While the increased usage of volar plating was intended to avoid the high frequency of tendon complications in dorsal plating, these complications have not been eliminated entirely, and the volar plate is associated with additional complications that do not commonly occur with

52 dorsal plates.(27) These complications include, but are not limited to: nerve dysfunction, tendon 53 dysfunction, and hardware failure. The remainder of this review will focus on the complications 54 associated with volar locked plating of distal radius fractures.

TENDON INJURY:

Extensor tendon injuries can result as a complication of distal radius fractures

58 independent of treatment method.(28-31) Recent systematic reviews have reported the incidence 59 of this extensor tendon rupture as $0.4 \%(6 / 1,359)$ with conservative management(32) and $1.5 \%$ $60(15 / 1,032)$ with dorsal plating.(33) However, the incidence of this injury has been shown to be 61 substantial following volar plate fixation of distal radius fractures, with reported rates ranging 62 from 0-4\%.(34-39) While multiple extensor tendons are at risk, including the extensor digitorum 63 communis and extensor indicis,(40) the extensor pollicis longus (EPL) tendon is the most 64 frequently affected. Zenke et al(34) reported EPL rupture in $2 \%$ of a cohort of 286 patients 65 treated with volar plating, while Tarallo et al(35) reported EPL rupture rate of $1 \%$ in a cohort of 66303 patients.

67 Incidence of extensor tendon injury has also been shown to be related to not only 68 placement of excessively long screws that are prominent dorsally, but also from direct drill-bit 69 penetration and irritation from bone fragments or comminution dorsally (FIGURE 5).(41-43)

70 Methods to avoid extensor tendon injury revolve around attention to proper surgical technique, 
71 accurate placement of the plate volarly, precise screw length selection to avoid dorsal screw

72 prominence, or the use of locking pegs instead of screws to avoid the sharp tip of a screw.(40,

73 44) Prompt implant removal is recommended upon early signs of extensor tendon irritation.(42)

74 Flexor tendon injury is a major but uncommon complication of volar plating, as it does

75 not usually occur due to the longer distance between flexor tendons and the proximal volar

76 cortex of the distal radius, the recessed nature of the volar plate relative to the volar rim or

77 watershed line of the distal radius, and the potential benefit of a repaired pronator quadratus over

78 the volar plate.(45) When flexor tendon rupture does occur, it most frequently affects the flexor

79 pollicis longus (FPL) tendon, although other tendons such as the flexor digitorum profundus may

80 also rupture.(46) While one study has reported the rate of flexor tendon rupture to be as high

$8111 \%,(47)$ the majority of recent studies report no flexor tendon injury at all.(48-51) Brennan et

82 al(51) reported no cases of flexor tendon injury in a series of 151 patients treated with volar 83 plating.

The incidence of flexor tendon injury has been shown to be related to prominence of the

85 implant relative to the watershed line of the distal radius, where the flexor tendons would lie

86 closest to the plate or its subchondral locking screws, malreduction of the fracture with residual

87 dorsal angulation increasing plate prominence, or loose or prominent subchondral locking screws

88 (FIGURE 6).(52-56) Among the reported flexor tendon ruptures, the median interval between

89 surgery and rupture was 9 months (range 6-26), highlighting the importance of symptom

90 monitoring at final follow-up.(46) Additionally, the mean age of patients with flexor tendon

91 injuries is 61 years with a female predominance.(46, 57) Factors that may avoid flexor tendon

92 injury include placement of the volar plate proximal to the watershed line, confirming that all

93 subchondral locking screws are locked and flush, and early removal of the plate upon signs of 
94 tendon dysfunction such as pain, crepitus, or triggering.(58) Closure of the pronator quadratus

95 muscle over the plate has also been suggested to decrease incidence of flexor tendon injury.(59-

96 61) However, there is no evidence that repair or closure of the pronator quadratus muscle is

97 efficacious when the distal radius is anatomically reduced and the volar plate is properly

98 positioned.(62-66)

99 In addition to tendon rupture, tenosynovitis is a frequent, though less severe,

100 complication of volar plating. Among the available literature, rates of tenosynovitis appear to be

101 similar for both the extensor and flexor tendons, varying from 0-3.8\% for extensor tendons and

$1020-3.8 \%$ for flexor tendons. $(8,35,48,51,67)$ The methods for preventing these injuries are

103 largely similar to those for preventing tendon rupture, but treatment relies largely on

104 symptomatic relief and immobilization rather than re-operation.

105

106 NERVE:

107

Carpal tunnel syndrome (CTS) is the most common nervous tissue-related complication

109 after distal radius fracture regardless of treatment method, with reported rates ranging from 0-

$11020 \%$ with conservative management(69-72) and $0-14 \%$ with volar plating. $(42,48,68,73,74)$

111 Zhao et al compared 7 treatment methods for distal radius fractures, including volar plating, and

112 found no significant difference in the incidence of CTS among the different treatment

113 options.(75) In a series of 282 patients treated with volar plating, Ho et al found an incidence of

114 CTS of $3.2 \%,(76)$ which is similar to the $3.8 \%$ incidence in the general population.(77) With this

115 in mind, it is a challenge to determine the true incidence of CTS following volar plate fixation.

116 Moreover, determining this incidence is further complicated by the fact that a carpal tunnel 
117 release (CTR) is often done prophylactically with volar plating of distal radius fractures in 118 various published series. $(78,79)$

While the existence of a cause-and-effect relationship of volar plating and CTS is not entirely clear, and performing prophylactic CTR remains controversial, it remains essential to

121 perform a thorough history and physical in all distal radius fracture patients to identify CTS

122 symptoms prior to operative management, and care should be taken not to injure the median 123 nerve during surgery.(80) In fact many of the median nerve injuries seen post-operatively are 124 likely related to intra-operative damage rather than compressive neuropathy and would not 125 respond to carpal tunnel release. Moreover, the risk factors for CTS after distal radius fracture 126 should be understood and include: fracture severity and displacement resulting in nerve 127 contusion or compression (FIGURE 7), prolonged deformity and swelling, prominent hardware, 128 retractor placement intra-operatively, use of an extensile carpal tunnel approach rather than a 129 trans-FCR or Henry surgical approach,(81) and post-operative splinting or casting tight or in 130 wrist flexion.(82) Frequency of surgical carpal tunnel release following this complication varies 131 widely, with release rates from 0-100\% reported for CTS as a complication of both conservative 132 and operative management.

Beyond CTS, complex regional pain syndrome (CRPS), formerly known as reflex

134 sympathetic dystrophy (RSD), is the second most commonly reported nervous tissue-related 135 complication following volar plating of distal radius fractures, with reported incidence ranging 136 from $0-9 \% .(37,38,42,68,83)$ However, due to its variable presentation and inconsistent 137 diagnostic criteria, the exact incidence is difficult to compute. As CRPS is a challenging and 138 potentially devastating complication, emphasis must be placed on early recognition and emergent 139 treatment. The primary feature of CRPS is continued pain out of proportion to the injury, but it is 
140 often associated with hyperesthesia, changes in skin blood flow, edema, and restriction of

141 motion, among other manifestations. $(84,85)$

Although a consensus for management of CRPS has yet to be established, there exists

143 evidence in support of the use of pain management, intravenous immunoglobulin (IVIG), aerobic

144 exercise, intrathecal clonidine/baclofen, mirror therapy, and many other treatments.(86) Because

145 no single treatment option has emerged as being superior, clinicians should focus on starting

146 multimodal therapy as early as possible. Some recent efforts have aimed at prevention with

147 prophylactic vitamin C supplementation.(87-89) In a systemic review and meta-analysis of 875

148 patients given prophylactic vitamin C after wrist fracture, Aïm et al found that daily

149 supplementation with $500 \mathrm{mg}$ for 50 days leads to a significantly decreased risk of developing

150 CRPS (RR 0.54 [95\% CI, 0.33-0.91]; P=0.02).(87) However, more recent studies have called

151 into question the efficacy of Vitamin C in preventing CRPS. $(89,90)$

152 Additional nervous-tissue-related complications with volar plating that have been

153 reported include injury to the palmar cutaneous branch of the median nerve $(92,93)$ and radial

154 and ulnar nerve neuropathies, $(74,94)$ but these are all less frequent.

155

HARDWARE:

157 Hardware-related complications appear to be less common than both tendon and nerve-

158 related complications with volar plating of distal radius fractures. Reported rates of hardware

159 complications range from $0-7 \%$, with malunion being the most commonly reported problem.(38,

$16048,51,68,74)$ (FIGURE 6 \& 8) Other hardware-related complications include screw loosening,

161 intra-articular screw placement, loss of reduction, and broken plate and screws. In a prospective

162 study of 228 patients treated with volar plating, Lattmann et al reported a hardware complication 
163 rate of $0.9 \%(2 / 228),(38)$ with both being a result of loss of reduction. A similarly large study by

164 Wichlas et al that retrospectively studied 225 patients treated by volar plate reported only one

165 hardware complication (malunion), resulting in a $0.4 \%(1 / 225)$ complication rate.(48) However,

166 a prospective study of 100 patients treated by volar plate conducted by Kato et al found a

167 hardware complication rate of 7\% (7/100), all of which were malunions.(74) Care should be

168 taken intra-operatively to prevent malunion by ensuring anatomic reduction with minimal dorsal

169 angulation, proper placement of locking screws in subchondral bone, and sufficient depth of

170 screws. While bone grafting is often used for fractures with large bone gaps, they are associated

171 with significant morbidity,(95) and recent evidence supports the notion that bone grafting is not

172 necessary with the use of volar plating. $(35,96,97)$ If malunion occurs despite these measures,

173 corrective osteotomy should be performed as soon as the diagnosis is confirmed

174 radiographically.(98)

175

176

OTHER COMPLICATIONS:

Other complications that may be encountered with volar plating of distal radius fracture

178 include but are not limited to finger or wrist contracture, chronic pain, trigger finger, or

179 radioulnar synostosis. Additionally, there are many inherent complications with any surgical

180 operation including infection, incision dehiscence, cellulitis, abscess, and hematoma. Of these,

181 infection appears to be the most common, affecting between $0-2.6 \%$ of patients. $(35,48,51,83$,

182 99) There exist also complications specific to any plating, that are not specific to the plate type,

183 such as re-fracture or peri-prosthetic fracture secondary to new trauma.

184 Additionally, many patients have their plates removed for a number of reasons. While some

185 plates are removed as a result of other complications such as tendon rupture, infection, or 
malunion, many patients request to have their plates removed for discomfort associated with the retained plate, decreased range of motion, pain, or anxiety related to the plate. It appears as though the all-cause incidence of hardware removal lies between $0-26 \%,(35,48,49,51,100)$ with significant variation depending on clinician preference.

\section{VOLAR PLATE SPECIFIC COMPLICATIONS:}

Currently, a number of volar plate options exist, including fixed-angle and variable-angle locking plates, with their own potential complication profiles:

\section{FIXED-ANGLE LOCKING PLATES:}

Locking plates were initially introduced to manage fractures in osteoporotic bone, bridging severely comminuted fractures, repairing articular fractures, and plating fractures that cannot be plated on the tension side of the bone.(24) As they have grown in popularity, volar locking plates are now the most frequently used form of implant used for internal fixation of distal radius fractures.(101) Reported rates of tendon complications range from $0-4.5 \%$, with the EPL being the most commonly affected tendon.(38, 48, 51, 74, 94, 99, 102, 103) In a retrospective review of 206 patients treated with volar locking plates, Johnson et al found four cases of tendon rupture, including three EPL ruptures $(1.5 \%)$ and one FPL rupture $(0.5 \%) .(103)$ Rates of nerve complications range from $0.4-14 \%$, with CTS being the most commonly reported type.(38, 48, 51, 74, 94, 99, 102, 103) One large multi-institutional retrospective study by Satake et al identified 694 patients treated by volar locking plate, of which only 4 cases of tendon rupture $(0.6 \%)$ were reported, while 18 cases of CTS (2.6\%) and 3 cases of CRPS $(0.4 \%)$ were reported, indicating a greater incidence of nerve complications than tendon complications.(93) 
Reported rates of hardware-related complications range from $0-7 \%$, with malunion being the most frequent.(38, 48, 51, 74, 94, 99, 102, 103)

Some studies have also directly compared the outcomes of volar non-locking and volar locking plates. One study by Obert et al retrospectively compared 31 patients treated by volar plating with non-locking screws to 121 patients treated by volar plating with locking screws and found no significant difference in the overall complication rates of the two groups $(16.1 \%$ vs. $16.5 \%)$. However, no patients in the non-locking group experienced tendon ruptures, while 6 patients (5\%) in the locking group did.(104) Another smaller study by Schmelzer-Schmied et al prospectively compared 15 patients treated with external fixation to 15 patients with non-locking and 15 patients with locking volar plates, finding that there were fewer complications in the volar plate groups but no difference between non-locking and locking plates (6\% vs. 13\%).(105) Zhang et al, in a retrospective comparison of 32 patients receiving non-locking to 25 patients receiving locking volar plates, found 10 complications (31\%) in the non-locking plate group and five in the locking plate group (20\%). Similarly, there were fewer major complications requiring re-operation in the locking plate group (1/25 vs. 4/32). No tendon ruptures were seen in either group.(106)

\section{VARIABLE-ANGLE LOCKING PLATES:}

Variable-angle, or poly-axial, locking plates are designed to allow the surgeon flexibility in placing the subchondral screws, and optimize placement of screws into the articular fragments, target higher quality bone, and more precisely avoid joint penetration.(26) In theory, this should allow for a more stable fixation and easier evasion of complications. In practice, reported tendon complication rates vary from $0-4 \%$, with extensor tendon rupture being the most 
232 commonly reported complication. $(49,68,83,92,107,108)$ Reported rates of nerve

233 complications range from $0.3-8 \%$, with carpal tunnel syndrome being most common. $(49,68,83$,

234 107-109) Hardware complication rates are reported between 0-4\%, with many studies reporting

235 no hardware related complications at all. $(49,83,92,107,108)$ Of the studies reporting hardware

236 complications, malunion, screw loosening, and intra-articular screws were the only types

237 witnessed. $(68,109)$ In a prospective study of 37 patients treated with variable angle volar

238 locking plates, Fowler and Ilyas reported one case of extensor tenosynovitis (3\%) from

239 prominent dorsal screw penetration that required re-operation and one case of loosening and

240 backing out of subchondral variable-angle locking screws (3\%) that did not require further

241 management. However, no nerve-related complications were reported.(11)

242 In addition, there have been multiple studies that have directly compared fixed and

243 variable-angle volar plates. In a retrospective chart review that included 60 patients receiving

244 fixed-angle plates and 148 receiving variable-angle plates, Mehrzad and Kim found that while

$24512 \%(7 / 60)$ of the patients in the fixed-angle group had hardware complications requiring re-

246 operation, none of the 148 patients receiving variable-angle plates had hardware complications

247 ( $\mathrm{p}<0.001) .(110)$ Marlow et al, in a retrospective study that included 42 patients receiving fixed-

248 angle plates and 65 receiving variable-angle plates, found that $12 \%(5 / 42)$ had complications $(2$

249 reduced ROM, 1 EPL tendonitis, 2 malunion) in the fixed angle group, and 8\% (5/65) had

250 complications (reduced ROM, 1 CTS, 2 CRPS) in the variable angle group, with no significant

251 difference between the two.(67)

252

253 CONCLUSION: 
All referenced studies used for complication rate computation are level I or II evidence, 255 and no case series or case-control studies were included. Based on the available literature, the 256 overall complication rate associated with volar locked plating of distal radius fractures is 257 substantial, however may be relatively low in comparison to other operative fixation methods. 258 While reported rates vary, nerve-related complications seem to be the most common type, 259 although many of these are likely attributable to the fracture itself and pre- or peri-operative 260 median nerve dysfunction, as opposed to the plate fixation. Tendon-related complications are the 261 next most common, with extensor tendons apparently more vulnerable than flexor tendons.

262 Hardware-related complications also occur, albeit less frequently, with malunion being the most263 reported hardware failure. There has been much progress in the types of volar plates available.

264 The newer generation variable-angle plates may be associated with less hardware-related 265 complications as a result of more optimal placement of the screws/pegs into the distal fragments 266 than fixed-angle volar locking plates. There are many limitations in interpreting the relevant data and comparing the various 268 methods of distal radius fracture fixation. In addition to differing plate type preference among 269 different surgeons and institutions, it is likely that surgeon experience and technique play a large 270 role in the varying rates of complications. Also, no two fractures are the same, and while all of 271 the fractures analyzed by these studies have been labeled as distal radius fractures, it remains a 272 challenge to know with certainty that reported complications are not related to the fracture 273 morphology and patient characteristics than the plate itself. While nearly all studies report the 274 AO classification of the fractures studied, the reported complications are rarely if ever sorted out 275 by fracture type, thereby leaving room for confounding variables. 
Volar plating of distal radius fractures appears to have a reasonable complication profile

277 and has emerged as a preferred method of internal fixation for distal radius fractures. However,

278 given their high costs and inconclusive functional benefits relative to conservative

279 management,(111) their costs and benefits should be addressed for all patients on an individual

280 basis. When choosing a volar plate, mixed angle locking plates were designed for use in

281 osteoporotic bone and severely comminuted fractures, and variable angle locking plates were

282 designed to allow targeting of higher quality bone and avoid joint penetration. However, there

283 does not seem to be one type of volar plate that is clearly superior in terms of functionality or

284 complication rates.(67) Therefore, care should be taken to carefully choose a plate according to

285 the patient's and fracture's characteristics in order to minimize complications. Similarly, careful

286 technique can likely significantly reduce the complication rates. As it appears that volar locked

287 plating of distal radius fractures will likely remain popular for the foreseeable future, ongoing

288 efforts should focus on plate designs and operative techniques that maximize functionality and

289 minimize opportunity for complication.

291 SOURCE OF FUNDING:

292 No funding was used in this investigation. 


\section{REFERENCES:}

1. Karl JW, Olson PR, Rosenwasser MP. The Epidemiology of Upper Extremity Fractures in the United States, 2009. J Orthop Trauma 2015 Aug;29(8):242.

2. Kilgore ML, Morrisey MA, Becker DJ, Gary LC, Curtis JR, Saag KG, et al. Health care expenditures associated with skeletal fractures among Medicare beneficiaries, 1999-2005. J Bone Miner Res 2009 Dec;24(12):2050-5.

3. Nellans KW, Kowalski E, Chung KC. The Epidemiology of Distal Radius Fractures. Hand Clinics 2012;28(2):113-25.

4. Schneppendahl J, Windolf J, Kaufmann RA. Distal radius fractures: Current concepts. J Hand Surg 2012;37(8):1718-25.

5. Bales JG, Stern PJ. Treatment Strategies of Distal Radius Fractures. Hand Clin 2012;28(2):177-84

6. Sharma H, Khare GN, Singh S, Ramaswamy AG, Kumaraswamy V, Singh AK. Outcomes and complications of fractures of distal radius (AO type B and C): volar plating versus nonoperative treatment. J Orthop Sci 2014 Jul;19(4):537-44.

7. Chung KC, Shauver MJ, Birkmeyer JD. Trends in the United States in the treatment of distal radial fractures in the elderly. Journal of Bone and Joint Surgery - Series A 2009;91(8):1868-73.

8. Arora R, Gabl M, Gschwentner M, Deml C, Krappinger D, Lutz M. A comparative study of clinical and radiologic outcomes of unstable Colles type distal radius fractures in patients older than 70 years: Nonoperative treatment versus volar locking plating. $\mathbf{J}$ Orthop Trauma 2009;23(4):237-42. 
9. Rozental TD, Beredjiklian PK, Bozentka DJ. Functional outcome and complications following two types of dorsal plating for unstable fractures of the distal part of the radius. J Bone Joint Surg Am 2003 Oct;85-A(10):1956-60.

10. Koval KJ, Harrast JJ, Anglen JO, Weinstein JN. Fractures of the distal part of the radius. The evolution of practice over time. Where's the evidence? J Bone Joint Surg Am 2008 Sep;90(9):1855-61.

11. Fowler JR, Ilyas AM. Prospective evaluation of distal radius fractures treated with variable-angle volar locking plates. J Hand Surg Am 2013 Nov;38(11):2198-203.

12. Terral TG, Freeland AE. Early salvage reconstruction of severe distal radius fractures. Clin Orthop Relat Res 1996 Jun;(327)(327):147-51.

13. Freeland AE, Sud V, Jemison DM. Early wrist arthrodesis for irreparable intra-articular distal radial fractures. Hand Surg 2000 Dec;5(2):113-8.

14. Smith RS, Crick JC, Alonso J, Horowitz M. Open reduction and internal fixation of volar lip fractures of the distal radius. J Orthop Trauma 1988;2(3):181-7.

15. Keating JF, Court-Brown CM, McQueen MM. Internal fixation of volar-displaced distal radial fractures. J Bone Joint Surg Br 1994 May;76(3):401-5.

16. Ring D, Jupiter JB. Operative fixation of fractures of the distal radius using the pi plate. Tech Hand Up Extrem Surg 1997 Jun;1(2):125-30.

17. Kambouroglou GK, Axelrod TS. Complications of the AO/ASIF titanium distal radius plate system (pi plate) in internal fixation of the distal radius: a brief report. J Hand Surg Am 1998 Jul;23(4):737-41.

18. Schnur DP, Chang B. Extensor tendon rupture after internal fixation of a distal radius fracture using a dorsally placed AO/ASIF titanium pi plate. Arbeitsgemeinschaft fur 

May;44(5):564-6.

19. Lowry KJ, Gainor BJ, Hoskins JS. Extensor tendon rupture secondary to the AO/ASIF titanium distal radius plate without associated plate failure: a case report. Am J Orthop (Belle Mead NJ) 2000 Oct;29(10):789-91.

20. Nunley JA, Rowan PR. Delayed rupture of the flexor pollicis longus tendon after inappropriate placement of the pi plate on the volar surface of the distal radius. $\mathrm{J}$ Hand Surg Am 1999 Nov;24(6):1279-80.

21. Orbay JL. The treatment of unstable distal radius fractures with volar fixation. Hand Surg 2000 Dec;5(2):103-12.

22. Orbay JL, Leone J. Volar fixation system with articulating stabilization pegs. 2002.

23. Orbay JL, Fernandez DL. Volar fixed-angle plate fixation for unstable distal radius fractures in the elderly patient. J Hand Surg Am 2004 Jan;29(1):96-102.

24. Egol KA, Kubiak EN, Fulkerson E, Kummer FJ, Koval KJ. Biomechanics of locked plates and screws. J Orthop Trauma 2004 Sep;18(8):488-93.

25. Fernandez A. Variable angle locked bone fixation system. 2005.

26. Obert L, Rey PB, Uhring J, Gasse N, Rochet S, Lepage D, et al. Fixation of distal radius fractures in adults: a review. Orthop Traumatol Surg Res 2013 Apr;99(2):216-34.

27. Wei J, Yang TB, Luo W, Qin JB, Kong FJ. Complications following dorsal versus volar plate fixation of distal radius fracture: a meta-analysis. J Int Med Res 2013 Apr;41(2):265-75.

28. Helal B, Chen SC, Iwegbu G. Rupture of the extensor pollicis longus tendon in undisplaced Colles' type of fracture. Hand 1982 Feb;14(1):41-7. 
29. Hirasawa Y, Katsumi Y, Akiyoshi T, Tamai K, Tokioka T. Clinical and microangiographic studies on rupture of the E.P.L. tendon after distal radial fractures. J Hand Surg Br 1990 Feb;15(1):51-7.

30. Roth KM, Blazar PE, Earp BE, Han R, Leung A. Incidence of extensor pollicis longus tendon rupture after nondisplaced distal radius fractures. J Hand Surg Am 2012 May;37(5):942-7.

31. Skoff HD. Postfracture extensor pollicis longus tenosynovitis and tendon rupture: a scientific study and personal series. Am J Orthop (Belle Mead NJ) 2003 May;32(5):2457.

32. White BD, Nydick JA, Karsky D, Williams BD, Hess AV, Stone JD. Incidence and clinical outcomes of tendon rupture following distal radius fracture. J Hand Surg Am 2012 Oct;37(10):2035-40.

33. Azzi AJ, Aldekhayel S, Boehm KS, Zadeh T. Tendon Rupture and Tenosynovitis following Internal Fixation of Distal Radius Fractures: A Systematic Review. Plast Reconstr Surg 2017 Mar;139(3):724e.

34. Zenke Y, Sakai A, Oshige T, Moritani S, Menuki K, Yamanaka Y, et al. Extensor pollicis longus tendon ruptures after the use of volar locking plates for distal radius fractures. Hand Surg 2013;18(2):169-73.

35. Tarallo L, Mugnai R, Zambianchi F, Adani R, Catani F. Volar plate fixation for the treatment of distal radius fractures: analysis of adverse events. J Orthop Trauma 2013 Dec;27(12):740-5. 
36. Thorninger R, Madsen ML, Waever D, Borris LC, Rolfing JHD. Complications of volar locking plating of distal radius fractures in 576 patients with 3.2 years follow-up. Injury 2017 Jun;48(6):1104-9.

37. Lattmann T, Dietrich M, Meier C, Kilgus M, Platz A. Comparison of 2 Surgical Approaches for Volar Locking Plate Osteosynthesis of the Distal Radius. J Hand Surg 2008;33(7):1135-43.

38. Lattmann T, Meier C, Dietrich M, Forberger J, Platz A. Results of volar locking plate osteosynthesis for distal radial fractures. Journal of Trauma - Injury, Infection and Critical Care 2011;70(6):1510-8.

39. Gruber G, Zacherl M, Giessauf C, Glehr M, Fuerst F, Liebmann W, et al. Quality of life after volar plate fixation of articular fractures of the distal part of the radius. Journal of Bone and Joint Surgery - Series A 2010;92(5):1170-8.

40. Rampoldi M, Marsico S. Complications of volar plating of distal radius fractures. Acta Orthop Belg 2007 Dec;73(6):714-9.

41. Sugun TS, Karabay N, Gurbuz Y, Ozaksar K, Toros T, Kayalar M. Screw prominences related to palmar locking plating of distal radius. J Hand Surg Eur Vol 2011 May;36(4):320-4.

42. Arora R, Lutz M, Hennerbichler A, Krappinger D, Espen D, Gabl M. Complications following internal fixation of unstable distal radius fracture with a palmar locking-plate. $\mathbf{J}$ Orthop Trauma 2007;21(5):316-22.

43. Benson EC, DeCarvalho A, Mikola EA, Veitch JM, Moneim MS. Two potential causes of EPL rupture after distal radius volar plate fixation. Clin Orthop Relat Res 2006 Oct; 451:218-22. 
44. Baumbach SF, Synek A, Traxler H, Mutschler W, Pahr D, Chevalier Y. The influence of distal screw length on the primary stability of volar plate osteosynthesis--a biomechanical study. J Orthop Surg Res 2015 Sep 8;10:8.

45. Vasenius J. Operative treatment of distal radius fractures. Scand J Surg 2008;97(4):7.

46. Asadollahi S, Keith PP. Flexor tendon injuries following plate fixation of distal radius fractures: a systematic review of the literature. J Orthop Traumatol 2013 Dec;14(4):22734.

47. Arora R, Lutz M, Deml C, Krappinger D, Haug L, Gabl M. A prospective randomized trial comparing nonoperative treatment with volar locking plate fixation for displaced and unstable distal radial fractures in patients sixty-five years of age and older. J Bone Joint Surg Am 2011 Dec 7;93(23):2146-53.

48. Wichlas F, Haas NP, Disch A, Macho D, Tsitsilonis S. Complication rates and reduction potential of palmar versus dorsal locking plate osteosynthesis for the treatment of distal radius fractures. J Orthop Traumatol 2014 Dec;15(4):259-64.

49. Kawasaki K, Nemoto T, Inagaki K, Tomita K, Ueno Y. Variable-angle locking plate with or without double-tiered subchondral support procedure in the treatment of intra-articular distal radius fracture. J Orthop Traumatol 2014 Dec;15(4):271-4.

50. Gradl G, Mielsch N, Wendt M, Falk S, Mittlmeier T, Gierer P, et al. Intramedullary nail versus volar plate fixation of extra-articular distal radius fractures. Two year results of a prospective randomized trial. Injury 2014 Jan;45 Suppl 1:3.

51. Brennan SA, Kiernan C, Beecher S, O'Reilly RT, Devitt BM, Kearns SR, et al. Volar plate versus k-wire fixation of distal radius fractures. Injury 2016;47(2):372-6. 
52. Soong M, Earp BE, Bishop G, Leung A, Blazar P. Volar locking plate implant prominence and flexor tendon rupture. J Bone Joint Surg Am 2011 Feb 16;93(4):328-35. 53. Adham MN, Porembski M, Adham C. Flexor tendon problems after volar plate fixation of distal radius fractures. Hand (N Y) 2009 Dec;4(4):406-9.

54. Bell JS, Wollstein R, Citron ND. Rupture of flexor pollicis longus tendon: a complication of volar plating of the distal radius. J Bone Joint Surg Br 1998 Mar;80(2):225-6.

55. Tanaka Y, Aoki M, Izumi T, Fujimiya M, Yamashita T, Imai T. Effect of distal radius volar plate position on contact pressure between the flexor pollicis longus tendon and the distal plate edge. J Hand Surg Am 2011 Nov;36(11):1790-7.

56. Wilson J, Viner JJ, Johal KS, Woodruff MJ. Volar Locking Plate Fixations for Displaced Distal Radius Fractures: An Evaluation of Complications and Radiographic Outcomes. Hand (N Y) 2017 Jul 1:1558944717717505.

57. Oyen J, Gjesdal CG, Brudvik C, Hove LM, Apalset EM, Gulseth HC, et al. Low-energy distal radius fractures in middle-aged and elderly men and women--the burden of osteoporosis and fracture risk : A study of 1794 consecutive patients. Osteoporos Int 2010 Jul;21(7):1257-67.

58. Orbay JL, Touhami A. Current concepts in volar fixed-angle fixation of unstable distal radius fractures. Clin Orthop Relat Res 2006 Apr;445:58-67.

59. Tahririan MA, Javdan M, Motififard M. Results of pronator quadratus repair in distal radius fractures to prevent tendon ruptures. Indian J Orthop 2014 Jul;48(4):399-403.

60. Ahsan ZS, Yao J. The importance of pronator quadratus repair in the treatment of distal radius fractures with volar plating. Hand (N Y) 2012 Sep;7(3):276-80. 
61. Huang HK, Wang JP, Chang MC. Repair of Pronator Quadratus With Partial Muscle Split and Distal Transfer for Volar Plating of Distal Radius Fractures. J Hand Surg Am 2017 Nov;42(11):935.e5.

62. Mulders MAM, Walenkamp MMJ, Bos, F J M E, Schep NWL, Goslings JC. Repair of the pronator quadratus after volar plate fixation in distal radius fractures: a systematic review. Strategies Trauma Limb Reconstr 2017 Nov;12(3):181-8.

63. Fan J, Chen K, Zhu H, Jiang B, Yuan F, Zhu X, et al. Effect of fixing distal radius fracture with volar locking palmar plates while preserving pronator quadratus. Chin Med J (Engl) 2014;127(16):2929-33.

64. Hershman SH, Immerman I, Bechtel C, Lekic N, Paksima N, Egol KA. The effects of pronator quadratus repair on outcomes after volar plating of distal radius fractures. $\mathbf{J}$ Orthop Trauma 2013 Mar;27(3):130-3.

65. Tosti R, Ilyas AM. Prospective evaluation of pronator quadratus repair following volar plate fixation of distal radius fractures. J Hand Surg Am 2013 Sep;38(9):1678-84.

66. Brown EN, Lifchez SD. Flexor pollicis longus tendon rupture after volar plating of a distal radius fracture: pronator quadratus plate coverage may not adequately protect tendons. Eplasty 2011;11:e43.

67. Marlow WJ, Singhal R, Dheerendra S, Ralte P, Fischer J, Waseem M. Distal radius volar locking plates : Does a variable angle locking system confer a clinical advantage ? Acta Orthop Belg 2012;78(3):309-16.

68. Tarallo L, Mugnai R, Zambianchi F, Adani R, Catani F. Volar plate fixation for the treatment of distal radius fractures: Analysis of adverse events. J Orthop Trauma $2013 ; 27(12): 740-5$. 
69. Cooney WP,3rd, Dobyns JH, Linscheid RL. Complications of Colles' fractures. J Bone Joint Surg Am 1980;62(4):613-9.

70. Hove LM. Nerve entrapment and reflex sympathetic dystrophy after fractures of the distal radius. Scand J Plast Reconstr Surg Hand Surg 1995 Mar;29(1):53-8.

71. Bienek T, Kusz D, Cielinski L. Peripheral nerve compression neuropathy after fractures of the distal radius. J Hand Surg Br 2006 Jun;31(3):256-60.

72. Aro H, Koivunen T, Katevuo K, Nieminen S, Aho AJ. Late compression neuropathies after Colles' fractures. Clin Orthop Relat Res 1988 Aug;(233)(233):217-25.

73. Goehre F, Otto W, Schwan S, Mendel T, Vergroesen PP, Lindemann-Sperfeld L. Comparison of palmar fixed-angle plate fixation with K-wire fixation of distal radius fractures (AO A2, A3, C1) in elderly patients. Journal of Hand Surgery: European Volume 2014;39(3):249-57.

74. Kato S, Tatebe M, Yamamoto M, Iwatsuki K, Nishizuka T, Hirata H. The results of volar locking plate fixation for the fragility fracture population with distal radius fracture in Japanese women. Nagoya J Med Sci 2014;76(1-2):101-11.

75. Zhao HL, Wang GB, Jia YQ, Zhu SC, Zhang FF, Liu HM. Comparison of Risk of Carpal Tunnel Syndrome in Patients with Distal Radius Fractures After 7 Treatments. Med Sci Monit 2015 Sep 22;21:2837-44.

76. Ho AW, Ho ST, Koo SC, Wong KH. Hand numbness and carpal tunnel syndrome after volar plating of distal radius fracture. Hand (N Y) 2011 Mar;6(1):34-8.

77. Atroshi I, Gummesson C, Johnsson R, Ornstein E, Ranstam J, Rosen I. Prevalence of carpal tunnel syndrome in a general population. JAMA 1999 Jul 14;282(2):153-8. 
78. Gwathmey FW,Jr, Brunton LM, Pensy RA, Chhabra AB. Volar plate osteosynthesis of distal radius fractures with concurrent prophylactic carpal tunnel release using a hybrid flexor carpi radialis approach. J Hand Surg Am 2010 Jul;35(7):1088.e4.

79. Tannan SC, Pappou IP, Gwathmey FW, Freilich AM, Chhabra AB. The Extended Flexor Carpi Radialis Approach for Concurrent Carpal Tunnel Release and Volar Plate Osteosynthesis for Distal Radius Fracture. J Hand Surg Am 2015 Oct;40(10):2031.e1.

80. Berglund LM, Messer TM. Complications of volar plate fixation for managing distal radius fractures. J Am Acad Orthop Surg 2009 Jun;17(6):369-77.

\section{Pensy RA, Brunton LM, Parks BG, Higgins JP, Chhabra AB. Single-incision} extensile volar approach to the distal radius and concurrent carpal tunnel release: cadaveric study. J Hand Surg Am. 2010;35(2):217-22.

82. Niver GE, Ilyas AM. Carpal tunnel syndrome after distal radius fracture. Orthop Clin North Am 2012 Oct;43(4):521-7.

83. Phadnis J, Trompeter A, Gallagher K, Bradshaw L, Elliott DS, Newman KJ. Mid-term functional outcome after the internal fixation of distal radius fractures. Journal of Orthopaedic Surgery and Research 2012;7(1).

84. Harden RN, Bruehl S, Stanton-Hicks M, Wilson PR. Proposed new diagnostic criteria for complex regional pain syndrome. Pain Med 2007;8(4):326-31.

85. Ott S, Maihofner C. Signs and Symptoms in 1,043 Patients with Complex Regional Pain Syndrome. J Pain 2018 Feb 2.

86. Duong S, Bravo D, Todd KJ, Finlayson RJ, Tran Q. Treatment of complex regional pain syndrome: an updated systematic review and narrative synthesis. Can J Anaesth 2018 Feb 28. 
87. Aim F, Klouche S, Frison A, Bauer T, Hardy P. Efficacy of vitamin C in preventing complex regional pain syndrome after wrist fracture: A systematic review and metaanalysis. Orthop Traumatol Surg Res 2017 May;103(3):465-70.

88. Chen S, Roffey DM, Dion CA, Arab A, Wai EK. Effect of Perioperative Vitamin C Supplementation on Postoperative Pain and the Incidence of Chronic Regional Pain Syndrome: A Systematic Review and Meta-Analysis. Clin J Pain 2016 Feb;32(2):179-85.

89. Zollinger PE, Tuinebreijer WE, Breederveld RS, Kreis RW. Can vitamin C prevent complex regional pain syndrome in patients with wrist fractures? A randomized, controlled, multicenter dose-response study. J Bone Joint Surg Am 2007 Jul;89(7):142431.

90. Ekrol I, Duckworth AD, Ralston SH, Court-Brown CM, McQueen MM. The influence of vitamin $\mathrm{C}$ on the outcome of distal radial fractures: a double-blind, randomized controlled trial. J Bone Joint Surg Am 2014 Sep 3;96(17):1451-9.

91. Evaniew N, McCarthy C, Kleinlugtenbelt YV, Ghert M, Bhandari M. Vitamin C to Prevent Complex Regional Pain Syndrome in Patients With Distal Radius Fractures: A Meta-Analysis of Randomized Controlled Trials. J Orthop Trauma 2015 Aug;29(8):235.

92. Figl M, Weninger P, Liska M, Hofbauer M, Leixnering M. Volar fixed-angle plate osteosynthesis of unstable distal radius fractures: 12 months results. Arch Orthop Trauma Surg 2009;129(5):661-9.

93. Samson D, Power DM. Iatrogenic Injuries of the Palmar Branch of the Median Nerve Following Volar Plate Fixation of the Distal Radius. J Hand Surg Asian Pac Vol 2017 Sep;22(3):343-9. 
94. Satake H, Hanaka N, Honma R, Watanabe T, Inoue S, Kanauchi Y, et al. Complications of Distal Radius Fractures Treated by Volar Locking Plate Fixation. Orthopedics 2016 Sep 1;39(5):893.

95. Dimitriou R, Mataliotakis GI, Angoules AG, Kanakaris NK, Giannoudis PV. Complications following autologous bone graft harvesting from the iliac crest and using the RIA: a systematic review. Injury 2011 Sep;42 Suppl 2:3.

96. Haase SC, Chung KC. Management of malunions of the distal radius. Hand Clin 2012 May;28(2):207-16.

97. Mahmoud M, El Shafie S, Kamal M. Correction of dorsally-malunited extra-articular distal radial fractures using volar locked plates without bone grafting. J Bone Joint Surg Br 2012 Aug;94(8):1090-6.

98. Mathews AL, Chung KC. Management of complications of distal radius fractures. Hand Clin 2015 May;31(2):205-15.

99. Matschke S, Wentzensen A, Ring D, Marent-Huber M, Audigé L, Jupiter JB. Comparison of angle stable plate fixation approaches for distal radius fractures. Injury 2011;42(4):385-92.

100. Tan A, Chong A. Reasons for Implant Removal after Distal Radius Fractures. J Hand Surg Asian Pac Vol 2016 Oct;21(3):321-5.

101. Mignemi ME, Byram IR, Wolfe CC, Fan K-, Koehler EA, Block JJ, et al. Radiographic outcomes of volar locked plating for distal radius fractures. J Hand Surg 2013;38(1):40-8. 
102. Matschke S, Marent-Huber M, Audigé L, Wentzensen A, Höntzsch D, Neugebauer R, et al. The surgical treatment of unstable distal radius fractures by angle stable implants: A multicenter prospective study. J Orthop Trauma 2011;25(5):312-7. 103. Johnson NA, Cutler L, Dias JJ, Ullah AS, Wildin CJ, Bhowal B. Complications after volar locking plate fixation of distal radius fractures. Injury 2014;45(3):528-33.

104. Obert L, Loisel F, Huard S, Rochet S, Lepage D, Leclerc G, et al. Plate fixation of distal radius fracture and related complications. European Journal of Orthopaedic Surgery and Traumatology 2015;25(3):457-64.

105. Schmelzer-Schmied N, Wieloch P, Martini AK, Daecke W. Comparison of external fixation, locking and non-locking palmar plating for unstable distal radius fractures in the elderly. Int Orthop 2009;33(3):773-8.

106. Zhang X, Hu C, Yu K, Bai J, Tian D, Xu Y, et al. Volar locking plate (VLP) versus non-locking plate (NLP) in the treatment of die-punch fractures of the distal radius, an observational study. Int J Surg 2016 Oct;34:142-7.

107. Figl M, Weninger P, Jurkowitsch J, Hofbauer M, Schauer J, Leixnering M. Unstable distal radius fractures in the elderly ratient-volar fixed-angle plate osteosynthesis prevents secondary loss of reduction. Journal of Trauma - Injury, Infection and Critical Care 2010;68(4):992-8.

108. Sonderegger J, Schindele S, Rau M, Gruenert JG. Palmar multidirectional fixedangle plate fixation in distal radius fractures: Do intraarticular fractures have a worse outcome than extraarticular fractures? Arch Orthop Trauma Surg 2010;130(10):1263-8. 109. Vlček M, Jaganjac E, Pech J, Jonáš D, Kebrle R. Is minimally invasive application by intramedullary osteosynthesis in comparison with volar plating real benefit 
in the treatment of distal radius fractures? Bosnian journal of basic medical sciences /

Udruženje basičnih mediciniskih znanosti = Association of Basic Medical Sciences 2014;14(2):81-8.

110. Mehrzad R, Kim DC. Complication Rate Comparing Variable Angle Distal Locking Plate to Fixed Angle Plate Fixation of Distal Radius Fractures. Ann Plast Surg 2016 Dec;77(6):623-5.

111. Toon DH, Premchand RAX, Sim J, Vaikunthan R. Outcomes and financial implications of intra-articular distal radius fractures: a comparative study of open reduction internal fixation (ORIF) with volar locking plates versus nonoperative management. J Orthop Traumatol 2017 Sep;18(3):229-34. 
593 LEGEND:

594 FIGURE 1

595 First generation stainless steel T-shaped volar buttress plate (Synthes, Paoli, PA), requiring

596 repair with 3.5 cortical and / or 4.0 cancellous screws.

597

598 FIGURE 2

599 Second generation low profile and low contact volar plate (Synthes, Paoli, PA), requiring repair 600 with 2.7 cortical shaft screws and 2.4 subchondral screws or locking pegs.

601

602 FIGURE 3

603 Anatomic fixed-angle volar locking plate (Hand Innovations, Miami, PA).

604

605 FIGURE 4

606 Variable-angle volar locking plate (Globus, Audubon, PA), with locking subchondral screws or 607 pegs. (A) Anterior view (B) Lateral view.

608

609 FIGURE 5

610 A fixed-angle volar locking plate with long subchondral screws with prominence dorsally, 611 ultimately resulting in extensor tendon rupture.

612

613 FIGURE 6 
614 Case of a locking volar plate with early post-operative loss of fracture reduction resulting in a

615 malunion and secondary plate prominence on the volar side, ultimately resulting in flexor tendon 616 rupture.

617

618 FIGURE 7

619 Case of a high-energy distal radius fracture with displacement and swelling. Note the prominent 620 volar cortex (yellow circle) impinging on the median nerve with secondary nerve swelling and 621 contusion.

622

623 FIGURE 8

624 Fracture malunion due to a poorly positioned plate resulting in inadequate lunate fracture repair 625 and late fracture displacement of the lunate facet, referred to as facet escape, and volar 626 subluxation of the radiocarpal joint. 